\title{
Essential newborn care practice at four primary health facilities in conflict affected areas of Bossaso, Somalia: a cross-sectional study
}

Ribka Amsalu ${ }^{1 *}$ D, Catherine N. Morris ${ }^{2}$, Kingsley Chukwumalu ${ }^{3}$, Michelle Hynes ${ }^{4}$, Shehryar Janjua ${ }^{5}$, Alexia Couture ${ }^{4}$, Aimee Summers ${ }^{4}$, Amy Cannon ${ }^{2}$, Erin N. Hulland ${ }^{4}$ and Sabine Baunach ${ }^{6}$

\begin{abstract}
Background: Newborn mortality is increasingly concentrated in contexts of conflict and political instability. However, there are limited guidelines and data on the availability and quality of newborn care in conflict settings. In 2016, an interagency collaboration developed the Newborn Health in Humanitarian Settings Field Guide- Interim version (Field Guide). In this study, we sought to understand the baseline availability and quality of essential newborn care in Bossaso, Somalia as part of an investigation to determine the feasibility and effectiveness of the Field Guide in improving newborn care in humanitarian settings.
\end{abstract}

Methods: A cross-sectional study was conducted at four purposely selected health facilities serving internally displaced persons affected by conflict in Bossaso. Essential newborn care practice and patient experience with childbirth care received at the facilities were assessed via observation of clinical practice during childbirth and the immediate postnatal period, and through postnatal interviews of mothers. Descriptive statistics and logistic regression were employed to summarize and examine variation by health facility.

Results: Of the 332 pregnant women approached, 253 (76.2\%) consented and were enrolled. 97.2\% (95\% Cl: 94.4, 98.9) had livebirths and $2.8 \%(95 \% \mathrm{Cl}: 1.1,5.6)$ had stillbirths. The early newborn mortality was $1.7 \%(95 \% \mathrm{Cl}: 0.3,4.8)$. Nearly all [95.7\%, (95\% Cl: 92.4, 97.8)] births were attended by skilled health worker. Similarly, 98.0\% (95\% Cl: 95.3, 99. 3) of newborns received immediate drying, and $99.2 \%(95 \% \mathrm{Cl}: 97.1,99.9)$ had delayed bathing. Few $[8.6 \%$, (95\% Cl: $5.4,12.9)]$ received immediate skin-to-skin contact and the practice varied significantly by facility $(p<0.001)$. Onethird of newborns [30.1\%, (95\% Cl: 24.4, 36.2)] received early initiation of breastfeeding and there was significant variation by facility $(p<0.001)$. While almost all $[99.2 \%$, (95\% Cl: $97.2,100)]$ service providers wore gloves while attending births, handwashing was not as common [20.2\%, (95\% Cl: 15.4, 25.6)] and varied by facility $(p<0.001)$. Nearly all [92\%, (95\% Cl: 86.9, 95.5)] mothers were either very happy or happy with the childbirth care received at the facility.

Conclusion: Essential newborn care interventions were not universally available. Quality of care varied by health facility and type of intervention. Training and supervision using the Field Guide could improve newborn outcomes.

Keywords: Newborn care, Conflict settings, Childbirth satisfaction, Somalia

\footnotetext{
* Correspondence: ramsalu@savechildren.org

${ }^{1}$ Emergency Health, Department of Global Health, Save the Children, 2275

Sutter Street, San Francisco, CA 94115, USA

Full list of author information is available at the end of the article
}

(c) The Author(s). 2019 Open Access This article is distributed under the terms of the Creative Commons Attribution 4.0 International License (http://creativecommons.org/licenses/by/4.0/), which permits unrestricted use, distribution, and reproduction in any medium, provided you give appropriate credit to the original author(s) and the source, provide a link to the Creative Commons license, and indicate if changes were made. The Creative Commons Public Domain Dedication waiver (http://creativecommons.org/publicdomain/zero/1.0/) applies to the data made available in this article, unless otherwise stated. 


\section{Background}

The term 'humanitarian crisis' refers to a singular event or a series of events, such as armed conflict or natural disasters that threaten the health, safety or wellbeing of a population [1]. Humanitarian crisis can be acute, within 4-6 months following an event, or protracted [2]. Protracted crises are defined as "those environments in which a significant proportion of the population is acutely vulnerable to death, disease and disruption of livelihoods over a prolonged period of time. The governance of these environments is usually very weak, with the state having a limited capacity to respond to, and mitigate, the threats to the population, or provide adequate levels of protection." [3]. The health impact of a humanitarian crises is evidenced in the excess morbidity and mortality associated directly with the crisis and in the destruction of existing health systems [2]. In recent years, humanitarian crises have intensified in terms of complexity and scale, resulting in the largest global numbers of refugees and internally displaced persons (IDPs) seen in decades [4].

Studies have shown that children under 5 years of age (under-5) experience disproportionally elevated mortality in humanitarian crises [2]. Globally, of the ten countries with the worst neonatal mortality rate, five are experiencing humanitarian emergencies: Afghanistan, Somalia, South Sudan, Central African Republic, and Chad [7]. Earlier studies have associated increased child mortality with specific infectious disease outbreaks in the under-5 population $[2,6]$. However, with the decline in child mortality due to infectious diseases, the importance of death in the neonatal period (0-28 days of life) has increased and accounts for nearly $47 \%$ of under- 5 deaths [7, 11]. Additionally, the average annual reduction rate in neonatal mortality between 1990 and 2016 is much lower than that for children aged 1-59 months [7]. Mortality risk during the newborn period is highest at the time of birth and in the first $24 \mathrm{~h}$ of life when over one-third of newborn deaths occur; in total, nearly three-quarters of the mortality among newborns occurs within the first 7 days of life [12]. Inherently, armed conflict leads to disruption of health systems, dislocation of a population, loss of skilled health care workers, financial distress, and disruption in social networks and norms [5]. This disruption could lead to increased vulnerability of pregnant women and their newborns. Despite this high burden of newborn mortality in countries affected by humanitarian crises, special considerations of how to implement evidence-based newborn interventions in these areas are lacking [9]. A systematic review of evidence in public health interventions in humanitarian emergencies, by Blanchet and colleagues, revealed an absence of data on newborn health in humanitarian emergencies [10]. The few studies identified in the systematic review by Blanchet and colleagues on emergency obstetrics and delivery care, did not yield information on newborn health [10].
In a 2012 survey of providers in humanitarian settings, a lack of training and clinical guidelines was reported as a barriers in the provision of newborn care in humanitarian settings [13]. In response to the lack of technical guidelines and standards on newborn care in humanitarian settings, an interagency collaboration developed the Newborn Health in Humanitarian Settings: Field Guide (Field Guide) [14]. The evidence-based interventions referenced in the Field Guide, including essential newborn care, are proven to be effective in improving newborn survival, are feasible in low- and middle-income countries, and are recommended by the World Health Organization (WHO) [15].

Essential newborn care as defined by the WHO and explained in the Field Guide, are care practices and interventions provided to a newborn immediately after birth comprising thermal care, infection prevention, initiation of immediate breastfeeding within an hour after birth, and newborn resuscitation [15]. These interventions are recommended to be available at the primary health care level and can be provided by trained midlevel providers such as nurses and midwives [15].

Somalia, a country experiencing a protracted crisis, was selected as the site to investigate the feasibility and effectiveness of the Field Guide in improving quality of care. More than two decades of civil war in Somalia has resulted in the displacement of 2.5 million persons internally and across the border into neighboring countries $[18,19]$. Lack of skilled health workers, low coverage of services, and fragile governance characterize the health care system in Somalia. The Federal Ministry of Health $(\mathrm{MOH})$ was reestablished following the appointment of an internationally recognized government in 2012, after more than two decades of civil-war [20]. Limited financing capability of the $\mathrm{MOH}$ has meant that most $\mathrm{MOH}$ health facilities benefit from financial and/or technical support from nongovernmental organizations (NGOs) and United Nation (UN) agencies. There are three governance structures - Somaliland, Puntland, and South-Central [20]. While Puntland has had modest success in improving the health status of the population and building health systems compared to South-Central, newborn indicators remain poor [20]. The 2011 UNICEF Puntland Multiple Indicator Cluster Survey (MICS) reported that only 5\% of infants received exclusive breastfeeding at six-months of life and only $13 \%$ had an institutional delivery [20]. There is a dire lack of data on current practices during childbirth and the neonatal period in protracted crisis settings such as Somalia. Therefore, understanding the baseline information of current practices and services available, as well as the readiness of health facilities to provide newborn care is critical.

The humanitarian emergency directly affects Puntland:, the United Nations Office for the Coordination of Humanitarian Affairs (UN OCHA), reports instances of 
armed conflict and associated displacement in large parts of the country including Bossaso, Puntland [19]. Bossaso city hosts an estimated 69,000 IDPs [19], who are mostly in non-camp settlements and concentrated in the city where they have access to health care services at the health centers and the regional hospital.

As part of a larger pre and post intervention study aimed at investigating the feasibility and effectiveness of the Field Guide in improving newborn-care practices and quality of care at the primary health facility level, we conducted a baseline cross-sectional assessment. In this paper we share the findings of the baseline assessments. To our knowledge, this is the first study to assess essential newborn practices and health facility readiness to provide newborn care in Puntland, Somalia.

\section{Methods}

\section{Study Sites \& Study Population}

In Somalia, the health care system has four levels - hospitals, referral health center, primary health centers, and health posts. Puntland has eight hospitals and 79 health centers [20]. The health centers are the primary providers of reproductive health services including antenatal, delivery, and postnatal care [20]. In Bossaso city, six health centers and one hospital provide maternal and child services to IDPs and to the host community. In consultation with the Ministry of Health, we purposely selected four out of the six primary health facilities serving IDPs based on predefined selection criteria: the health facilities were open 24-h a day / 7 days a week and had an average of at least 40 deliveries per month.

The selected health facilities are staffed by midwives, nurses, auxiliary nurses, and community midwives (Table
1). The total catchment population of all selected health facilities was estimated at 134,735 persons, including IDPs and the host community.

\section{Eligibility}

Women were eligible to participate if they were between 15 and 49 years of age and presented at one of the study facilities during the project period to deliver a child. Women who were immediately referred to a hospital for delivery were excluded. Women who had a stillbirth or early newborn death were excluded from the postnatal home interview out of respect for the family.

\section{Study design}

We collected observation data over an eight-week period between August and October 2016. There were no marked social events, weather events or civil unrest during the study period. A sample of 203 mother-baby pairs was targeted for the longitudinal study to have sufficient power to detect statistically significant differences in outcomes before and after the implementation of the Field Guide - Essential Newborn Care component. The sample size was allocated across the four facilities using population proportionate to estimated size (PPES) based on the number of deliveries over a six-month period prior to the study period [21].

We collected data with two instruments- an observation checklist and a structured postnatal interview questionnaire. The observation checklist was adapted from previously validated tools $[25,26]$ based on the WHO's Managing Complications in Pregnancy and Childbirth Guide [17]; and the postnatal interview childbirth satisfaction questionnaire and Likert scale were adapted from

Table 1 Characteristics of Primary Health Centers

\begin{tabular}{|c|c|c|c|c|}
\hline & Health Facility 1 & Health Facility 2 & Health Facility 3 & Health Facility 4 \\
\hline Catchment population & 32,000 & 34,171 & 39,564 & 29,000 \\
\hline Number of women enrolled in the study & 55 & 95 & 58 & 45 \\
\hline Operating hours & $24 / 7$ & $24 / 7$ & $24 / 7$ & $24 / 7$ \\
\hline Running water $24 / 7$ & Yes & Yes & Yes & Yes \\
\hline Generator or power supply & Yes & No & Yes & Yes \\
\hline Labor room functional & Yes & Yes & Yes & Yes \\
\hline Maternity ward & Yes & Yes & Yes & Yes \\
\hline Newborn area or table for resuscitation & Yes & No & No & Yes \\
\hline Skilled health worker available $24 / 7$ & Yes & No & Yes & Yes \\
\hline \multicolumn{5}{|l|}{ Healthcare workers } \\
\hline Midwife & 4 & 3 & 4 & 3 \\
\hline Registered nurse & 3 & 3 & 3 & 6 \\
\hline Auxiliary nurse & 6 & 6 & 3 & 7 \\
\hline Community midwife & 2 & 2 & 3 & 0 \\
\hline Distance from referral hospital & $2 \mathrm{~km}$ & $2.5 \mathrm{~km}$ & $3 \mathrm{~km}$ & $3.4 \mathrm{~km}$ \\
\hline
\end{tabular}


a previously validated Mackey childbirth satisfaction rating scale $[22,23]$. The observation checklist had eight sections: maternal history; health facility labor room preparedness; delivery care and immediate newborn assessment; newborn thermal care; readiness for newborn resuscitation; support and initiation of early breastfeeding; routine care and prophylaxis provided (including pre-discharge education to mother on newborn care); and maternal and newborn outcomes. Observation started at the time of admission of the pregnant woman to the health facility for childbirth until her subsequent discharge from the health facility. The time spent at the health facility for each mother was recorded by trained observers.

\section{Measures of essential newborn care}

Essential newborn care interventions were defined using WHO guidance [15] under 4 categories: 1) thermal care, which consists of immediate drying (drying of newborn with towel at birth), delayed bathing ${ }^{1}$ (newborn did not receive bathing from birth to discharge from the health facility), and skin-to-skin contact (the placement of newborn on mother's chest after cord cutting with skin-to-skin contact and no barrier between newborn and mother); 2) feeding, which consists of assistance provided to the mother for the initiation of immediate breastfeeding (provider shows mother early signs of attachment to nipple and suckling), and early initiation of breastfeeding (start of breastfeeding within an hour after birth); 3) hygiene, which consists of provider handwashing (provider washes hands with water and soap prior to attending childbirth), provider wearing gloves (provider wears a pair of unused or sterile gloves prior to attending childbirth), clean delivery kit available (delivery kit in sterile wrap, placed on an instrument tray or similar, and ready for use), clean delivery bed available (visibly clean delivery bed ready for pregnant women to deliver on), and dry cord care (nothing placed on umbilical stump and stump is kept uncovered); and 4) readiness for newborn resuscitation, which was measured with the availability of printed partographs to monitor labor, fetoscope/ doppler for auscultation, self-inflating resuscitation bag, term mask, clean area in labor room for newborn resuscitation (resuscitation surface), and suction device.

Maternal obstetric history and interventions received during pregnancy were collected through a structured questionnaire, administered to the mother, including antenatal visits, tetanus toxoid vaccination during pregnancy, intermittent preventive treatment of malaria in pregnancy (IPTp), syphilis screening and treatment for urinary tract infection. These evidence-based interventions during pregnancy are associated with reduction in prematurity, low birth weight, and early neonatal infection [16].

\section{Data collection}

We collected data using tablets with KoBo Toolbox software [27]. Sixteen observers were trained on the observation checklist and consent process. We trained the observers using video based illustrations that demonstrate standard practice during labor, delivery, and immediately after birth. All observers were female, from the community, had a health background, and were not employees of the Ministry of Health. The observation tool was piloted for 2 days with pairing of observers to assess inter-observer agreement in observation (exact count agreement was $94.6 \%)^{2}$ and to evaluate their performance. To minimize the Hawthorne effect observers were selected from the community, decreasing the possibility of the observer being perceived as an outsider [28], while at the health facility, the observers wore similar uniforms to other health facility staff further creating a non-threatening perception $[28,29]$. In addition to the observers, we trained four female interviewers for 4 days on the postnatal interview data collection tool. Postnatal interviews were administered to mothers who consented to be visited at home on days 7-9 after birth discharge from the health center. In the absence of a proper home/residence address, data collectors depended on the phone number that was given by the mother prior to discharge to find the home for postnatal interview. If repeated phone calls were not answered, or if they were informed that the family had moved outside the Bosasso city limits, the mother-baby pair was recorded as lost to follow up.

Data were entered directly on tablets and were uploaded to Kobo Toolbox, and were exported to a Microsoft Excel database (Microsoft Excel 2016) daily. Validation rules were built into the tablet-based survey tool to prompt the observer on missing data or data that required review. Data quality was checked each day by the research coordinator. Any inconsistencies were verified immediately with the observers and were cross-checked with records at the health facility. The data collected did not have personal identifiers and codes used were de-identified prior to data sharing for analysis.

\section{Statistical analysis}

Descriptive analyses were performed and summarized with means and standard deviations for continuous variables and proportions with 95\% confidence intervals for categorical variables. Maternal age, parity, number of antenatal visits, tetanus toxoid vaccination, and gestational age were collected as continuous variables and were categorized for analysis. Observation of essential newborn practice and the immediate postnatal period were binary variables. We calculated the proportion and 95\% confidence interval of newborns who received interventions. Missing responses were identified and were excluded from 
the analysis. Logistic regression was used to examine variations in observed practices between health facilities. Statistical significance was defined as $p<0.05$. The postnatal interview Likert scale score was analyzed by estimating the proportion of response for each category. Recall of educational messages was binary (yes/no) and the proportion with $95 \%$ confidence interval was calculated. All analyses were performed using Stata version 14 (StataCorp. STATA Statistical Software: Release 14.0. 2015).

\section{Ethical approval and informed consent}

Approval for the study was sought and obtained from the Puntland Ministry of Health and from the Save the Children ethics review committee, and a non-research determination was approved by The Centers for Disease Control and Prevention (CDC). Women who presented to the health center for delivery care were approached by the study team. Consent information was read to the women in the local language, and verbal consent was sought. Those who consented were included in the study. Personal identifiers collected to facilitate the postnatal follow-up visit were destroyed immediately after completion of the data collection process. Consent was also sought and obtained from health care providers who were working in the four health facilities and who were directly involved in the provision of maternal and newborn care.

\section{Results}

\section{Obstetric history of study sample}

Overall, 380 pregnant women in labor presented at the health facilities during the study period of August-October 2016. Of those women, 48 (12.6\%) were referred to a hospital after assessment at arrival and were not approached for consent. Of the 332 women approached for consent, $253(76.2 \%)$ consented and were enrolled in the study. Among the 253 women enrolled, 245 (96.8\%) were eligible for home postnatal interview, with 8 participants ineligible due to stillbirth or early neonatal death. Eleven women declined and 58 women were lost to follow-up. Nearly three-quarters $(n=174,71.0 \%)$ were successfully interviewed at home 7 to 9 days after birth discharge (Fig. 1).

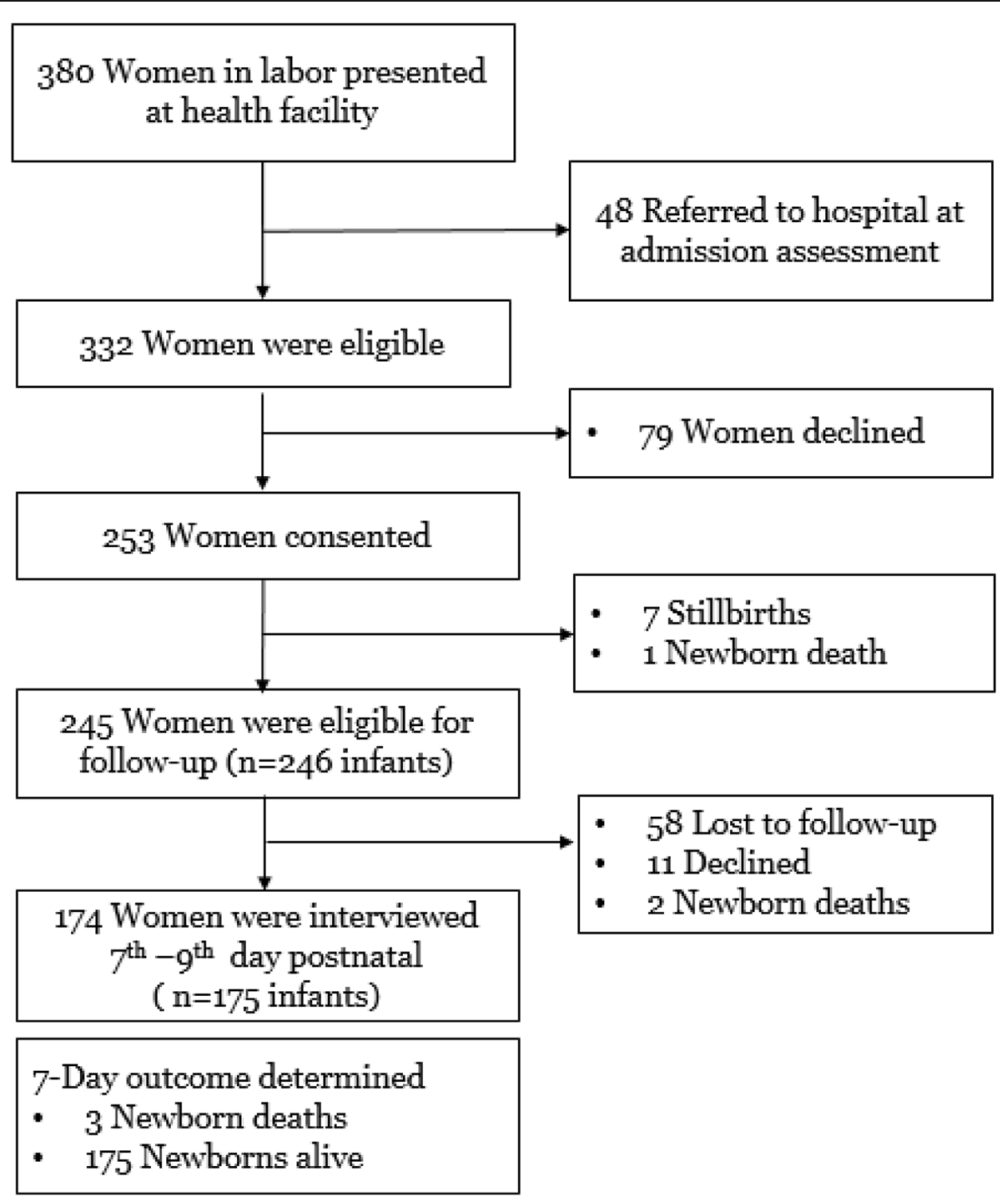

Fig. 1 Flowchart of Study Participants 
The median maternal age was 25 years (Interquartile range (IQR): $21-30$ ), and less than one-tenth [9\% (95\% CI: $5.9,13.3)$ ] of pregnant women were under the age of 19 years. One-fifth [19.8\% (95\% CI: 15.0, 25.2)] were primigravida. The majority [87.4\%, (95\% CI: 82.7, 91.3)] of women had prior contact with the health care system with at least one antenatal visit, and $14.2 \%$ (95\% CI: 10.1, 19.2) had four or more antenatal visits. ${ }^{3}$ The majority [70.8\%, (95\% CI: 64.7, 76.3)] of women were diagnosed with a urinary tract infection at an antenatal visit and, of those, 95.5\% (95\% CI: 91.4, 98.1) received antibiotics. Few [10.3\% (95\% CI: 6.8, 14.7)] had received intermittent preventive treatment for malaria during pregnancy while fewer still [9.1\% (95\% CI: 5.9-13.3)] had received screening for syphilis (Table 2).

\section{Delivery attendants \& birth outcomes}

The caseload at the four health facilities was similar, with 1-3 deliveries per 24-h period. Most [95.7\%, (95\%CI: 92.4, 97.8)] deliveries were attended by a skilled provider, usually a qualified midwife or nurse (Table 3). The birth outcomes were mostly singleton spontaneous vaginal deliveries, with one twin birth and no assisted vaginal deliveries. Overall, there were 97.2\% (95\% CI: 92.4, 98.9) live births, $2.8 \%$ (95\% CI: 1.1, 5.6) stillbirths, and 1.7\% (95\% CI: 0.3, 4.8) early newborn deaths (one newborn died prior to discharge at the health facility and two were reported at a postnatal visit to have died in the first week of life). The median gestational age was 38 weeks with $2.4 \%$ (95\% CI: $0.9,5.1$ ) of infants born preterm prior to completing 37 weeks of gestation. In terms of newborn complications, $4.5 \%$ (95\% CI: $2.2,7.9)$ of newborns needed resuscitation and all received resuscitation successfully. There were no maternal deaths.

\section{Essential newborn care by health facility (Table 4)}

The first category of essential newborn care, thermal care, had two of three components - drying immediately after birth and delayed bathing - practiced nearly universally in all the health facilities with an overall proportion of 98.0\% (95\% CI: 95.3, 99.3) and 99.2\% (95\% CI: 97.1, 99.9\%), respectively. Conversely, the third component of thermal care - skin-to-skin contact of newborns with their mother - was rare, with only $8.6 \%$ (95\% CI: 5.4 , 12.9) observed. There was significant variation between the facilities with a low of $1.9 \%(95 \% \mathrm{CI}: 0.2,9.9)$ in $\mathrm{Fa}-$ cility 1 and a high of $29.5 \%$ (95\% CI: 16.8, 45.2) in Facility $4(p<0.001)$ (Fig. 2). There was no statistically significant variation in skin-to-skin contact by parity or gestational age of newborn.

Table 2 Obstetric History \& Interventions Received During Pregnancy

\begin{tabular}{|c|c|c|}
\hline & $n / N$ & Proportion $(95 \% \mathrm{Cl})$ \\
\hline \multicolumn{3}{|l|}{ Maternal Age } \\
\hline $15-18$ years & $23 / 253$ & $9.1(5.9-13.3)$ \\
\hline 19-24 years & $78 / 253$ & $30.8(25.2-36.9)$ \\
\hline$\geq 25$ years & $152 / 253$ & $60.1(53.8-66.2)$ \\
\hline \multicolumn{3}{|l|}{ Gravidity } \\
\hline Primigravida & $50 / 253$ & 19.8(15.0-25.2) \\
\hline Two or more pregnancies & $203 / 253$ & $80.2(74.8-85.0)$ \\
\hline \multicolumn{3}{|l|}{ Antenatal Care (ANC) } \\
\hline None & $31 / 247$ & 12.6(8.7-17.3) \\
\hline One to three ANC visits & $181 / 247$ & $73.2(67.3-78.7)$ \\
\hline Four or more ANC visits & $35 / 247$ & $14.2(10.1-19.2)$ \\
\hline \multicolumn{3}{|l|}{ Interventions during current pregnancy } \\
\hline \multicolumn{3}{|l|}{ Tetanus toxoid vaccination } \\
\hline None & $78 / 250$ & $31.2(25.5-37.3)$ \\
\hline Received $1 \pi$ doses & $98 / 250$ & $39.2(33.1-45.6)$ \\
\hline Received $\geq 2 \pi$ doses & $74 / 250$ & $29.6(24.0-35.7)$ \\
\hline \multicolumn{3}{|l|}{ Urinary Tract Infections (UTI) } \\
\hline Had history of symptoms of UTI & $179 / 253$ & 70.8(64.7-76.3) \\
\hline Received antibiotics for symptoms of UTI & $171 / 179$ & $95.5(91.4-98.1)$ \\
\hline Received test for Syphilis & $23 / 253$ & $9.1(5.9-13.3)$ \\
\hline Received preventive treatment for Malaria (IPTp) & $26 / 253$ & 10.3(6.8-14.7) \\
\hline
\end{tabular}

${ }^{\mathrm{a} M e d i a n}$ maternal age was $25 \mathrm{yrs}$. with interquartile range of 21 years - 30 years 
Table 3 Birth Outcomes and Newborn Complications

\begin{tabular}{|c|c|c|}
\hline & $\mathrm{n} / \mathrm{N}$ & Proportion $(95 \% \mathrm{Cl})$ \\
\hline \multicolumn{3}{|l|}{ Birth Attendant } \\
\hline Skilled health worker ${ }^{\text {a }}$ & $242 / 253$ & 95.7(92.4-97.8) \\
\hline Non-skilled health worker ${ }^{b}$ & $11 / 253$ & $4.3(2.2-7.6)$ \\
\hline \multicolumn{3}{|l|}{ Birth Outcome } \\
\hline Live births $^{c}$ & $246 / 253$ & 97.2(94.4-98.9) \\
\hline Stillbirth & $7 / 253$ & $2.8(1.1-5.6)$ \\
\hline Early newborn death ${ }^{d}$ & $3 / 178$ & $1.7(0.3-4.8)$ \\
\hline \multicolumn{3}{|l|}{ Gestational age } \\
\hline$<37$ Weeks & $6 / 252$ & $2.4(1.9-3.0)$ \\
\hline$\geq 37$ Weeks & $246 / 252$ & $97.6(94.9-99.1)$ \\
\hline \multicolumn{3}{|l|}{ Newborn Complications ${ }^{f}$} \\
\hline Infection & $5 / 246$ & $2.0(0.7-4.7)$ \\
\hline Fast breathing & $4 / 246$ & $1.6(0.4-4.1)$ \\
\hline Birth Asphyxia & $11 / 246$ & $4.5(2.3-7.9)$ \\
\hline Congenital anomalies & $1 / 246$ & $0.4(0.0-2.2)$ \\
\hline
\end{tabular}

${ }^{a}$ Skilled health workers were Midwives who attended 229/242 or Registered Nurse who attended 13/242 births

${ }^{b}$ Non-skilled health workers were Auxiliary Nurses who attended 9/11 or Community Midwife who attended 2/11 births

'One of the deliveries was a twin livebirth

${ }^{\mathrm{d} D e f i n e d}$ as death within 7 days after birth. 1 death at health facility and 2 deaths at home. 7-day outcome determined among 178 newborns

${ }^{\mathrm{e}}$ Missing gestational age of 1 newborn

${ }^{f}$ More than one complication could have been reported by patient.

Denominator total livebirths with 1 twin birth

The second category of essential newborn care, breastfeeding, had $18.7 \%$ (95\% CI: 14.0, 24.2) of mothers receiving assistance by a health care worker in the initiation of immediate breastfeeding and 30.1\% (95\% CI: $24.4,36.2)$ of mothers initiating early breastfeeding within an hour after birth. Assistance by a health care worker in the initiation of breastfeeding and early initiation of breastfeeding both varied significantly by health facility $(p<0.001)$. There was no statistically significant difference in the initiation of early breastfeeding or support to breastfeeding by parity.

For the third category of essential newborn care, hygienic practice, nearly all [99.2\% (95\% CI: 97.2, 99.9)] health workers wore clean or sterile gloves to attend childbirth. However, hand washing was only practiced by $20.2 \%$ (95\%CI: 15.4, 25.6) of health workers prior to attending childbirth, and dry cord care was practiced for 40.7\% (95\% CI: $34.5,47.1$ ) of newborns. Hand washing by the health worker and dry cord care practice both varied significantly by health facility $(p<0.001)$, while sterile glove use was not significantly different between facilities.

Readiness for newborn resuscitation, the fourth category of newborn care, was lacking; printed partograph forms were available in 3.6\% (95\% CI: 1.6, 6.6) of deliveries, fetoscope or doppler for fetal heartbeat auscultation was available in the labor room during 26.9\% (95\% CI: $21.5,32.8)$ of deliveries, and there was a self-inflating resuscitation bag and term mask in the labor room in 15.0\% (95\% CI: $10.8,20.1 \%$ ) and $17.5 \%(95 \%$ CI: 12.9 , 22.8) of deliveries respectively.

\section{Observed postnatal care at health facility}

The observed median length of stay at the health facility after childbirth was $4 \mathrm{~h}$ and $37 \mathrm{~min}$ (IQR: $2 \mathrm{~h}$ and $25 \mathrm{~min}$ to $7 \mathrm{~h}$ and $8 \mathrm{~min}$ ). In routine care for newborns, $42.1 \%$ $(95 \%$ CI: 35.9, 48.6) received tetracycline eye ointment while only $4.1 \%$ (95\% CI: $2.0,7.4$ ) received vitamin K (Table 5). Health education and information provided to mothers prior to discharge was poor: $11.5 \%$ (95\% CI: 7.8 , 16.2) of mothers received information on hygiene, $10.3 \%$ (95\% CI: 6.8, 14.8) received information on dry cord care, $9.1 \%$ (95\% CI: $5.8,13.4)$ on danger signs, 3.7\% (95\% CI: $1.7,6.9)$ on skin-to-skin care, and $16.5 \%$ (95\% CI: $12.0,21.7)$ on the importance of breastfeeding.

\section{Postnatal interview on childbirth care experience}

Out of the 245 eligible women for postnatal home interviews, $174(71.0 \%)$ were successfully followed up at home 7 to 9 days following discharge from the facility. Of the 174 women who were interviewed, less than half [40.2\% (95\% CI: 32.9, 47.9)] reported receiving information on newborn care from health staff (Table 6). Of the women who reported receiving information on newborn care, $11.4 \%$ (95\%CI: 5.1, 21.3) of women recalled having received information on dry cord care as presented in Table 6. Overall, of the 174 women interviewed, $62.6 \%$ (95\% CI: 55.0, 69.8) reported receiving messages on breastfeeding and $13.2 \%$ (95\% CI: $8.7,19.2)$ on danger signs of newborn illness.

Across the four health facilities, the majority of women were either happy or very happy in the cleanliness of the clinic [98.9\%, (95\% CI: 95.9, 99.9)], privacy during service provision [98.3\%, (95\% CI: 95.0, 99.6)], confidentiality [94.8\%, (95\% CI: 90.4, 97.6)], friendliness of staff [94.8\%, (95\% CI: 90.4,97.6)], care received [94.8\%, (95\% CI: 90.4, 97.6)], response to questions asked [95.9\%, (95\% CI: 91.9, 98.4)], and timeliness of care provided (96.0\%, (95\% CI: 91.9, 98.4)] (Fig. 3). Of the five women who responded unhappy or very unhappy, 2 were unhappy or very unhappy in more than one domain and 4 were unhappy with the care provided. Regarding, where the mothers who responded unhappy or very unhappy received care, they were distributed in the three health facilities: 2 mothers delivered in health facility $1 ; 2$ delivered in health facility 2; and 1 delivered in health facility 3.

Overall, 92.0\% (95\% CI: 86.9, 95.5) of women reported that they were satisfied with the childbirth care provided at the health centers, 97.7\% (95\% CI: 94.2, 99.4) reported that they would return back to the health facility for 


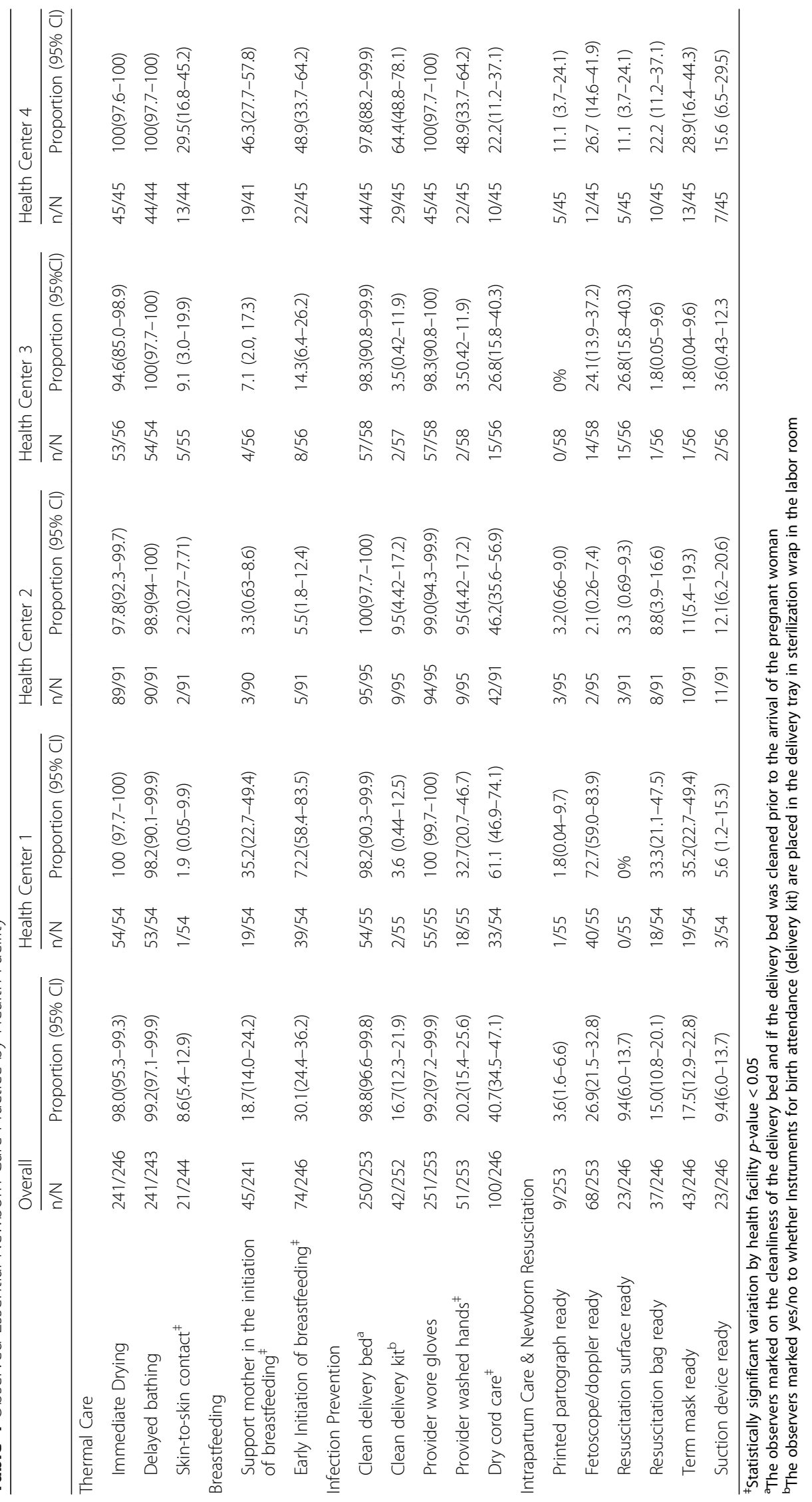




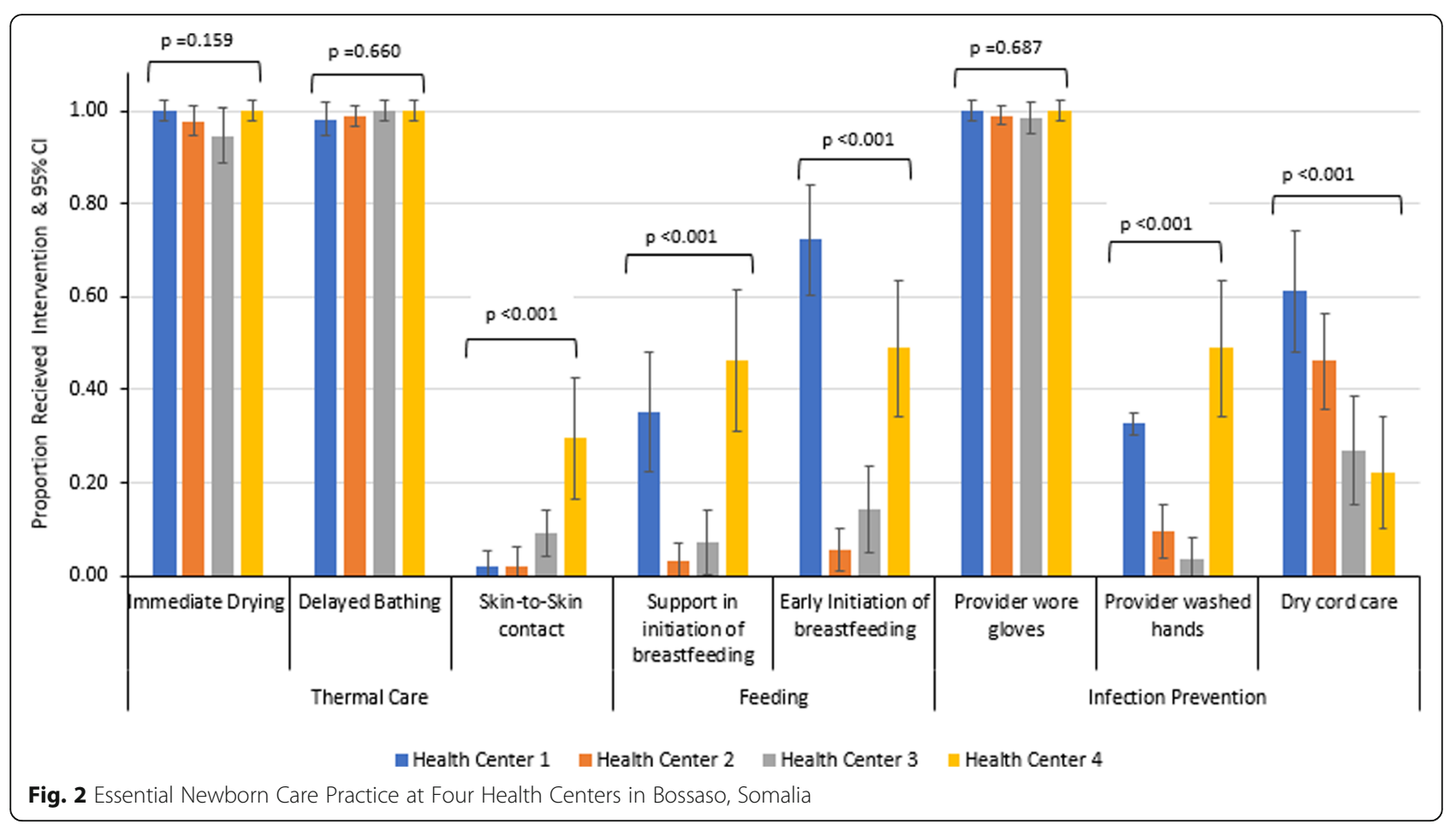

future health care needs, and $86.8 \%$ (95\% CI: 80.8, 91.4) responded that the health care worker provided their baby with the best care available as presented in Table 6 . We compared the mother-baby pairs that were visited/ followed up postnatally with those that were lost to

Table 5 Observed Postnatal Care Prior to Birth Discharge

\begin{tabular}{lll}
\hline & $\mathrm{n} / \mathrm{N}$ & Proportion (95\%Cl) \\
\hline $\begin{array}{l}\text { Length of Stay at Health } \\
\text { Facility After Childbirth }\end{array}$ & & \\
$\quad \leq 6 \mathrm{~h}$ & $161 / 242$ & $66.5(60.2-72.4)$ \\
$6-11 \mathrm{~h}$ & $61 / 242$ & $25.2(19.9-31.2)$ \\
$\geq 12 \mathrm{~h}$ & $20 / 242$ & $8.3(5.1-12.5)$ \\
Routine Care Pre-Discharge & & \\
$\quad$ Exam of newborn within & $150 / 246$ & $61.0(54.6-67.1)$ \\
30 min after birth & & \\
$\quad$ Tetracycline eye ointment & $102 / 242$ & $42.0(35.9-48.6)$ \\
$\quad$ Vitamin K injection & $10 / 243$ & $4.1(2.0-7.4)$ \\
Education Provided on & & \\
Newborn care to Mother \\
by Health Care Worker
\end{tabular}

aedian length of stay at the health facility after childbirth was $4 \mathrm{~h}$ and $37 \mathrm{~min}$ with inter-quartile range of $2 \mathrm{~h}$ and $25 \mathrm{~min}-7 \mathrm{~h}$ and $8 \mathrm{~min}$ follow up; there was no statistically significant difference in place of delivery, maternal age, or birth attendant between the two groups.

\section{Discussion}

Our study, conducted in a protracted conflict setting of Bossaso, Somalia, found that while the majority of the childbirths were attended by skilled health workers (midwives and nurses), the observed quality of care varied. The components of essential newborn care: thermal care, infection prevention, early initiation of breastfeeding, and readiness to provide newborn resuscitation, were not universally provided or available.

Access to health care and a skilled health provider is always a concern in humanitarian emergencies. In our study, the health centers selected were operational $24 \mathrm{~h}$ a day/7 day a week and had a skilled health care worker (nurse or midwife) available during all operating hours (Table 1). The percent of women who received at least one ANC visit was high (88\%) and was consistent with past studies where IDPs or refugees are concentrated in urban areas where geographic access to a health facility is not an impediment and there are no user fees at the point of care $[5,8]$. However, the quality of care found in our study was not optimal. While contact with the health facility as seen with at least one ANC visit was high $(88 \%)$, the interventions received during pregnancy, such as, screening for syphilis (9\%), were very low.

Although the two thermal care components of immediate drying of newborn and delayed bathing were nearly 
Table 6 Childbirth Experience and Maternal Knowledge of Newborn Care Practices

\begin{tabular}{|c|c|c|}
\hline Intervention & $\mathrm{n} / \mathrm{N}$ & Proportion $(95 \% \mathrm{Cl})$ \\
\hline $\begin{array}{l}\text { Recalled receiving information } \\
\text { on newborn care from health } \\
\text { care provider }\end{array}$ & 70/174 & $40.2(32.9-47.9)$ \\
\hline \multicolumn{3}{|l|}{ Type of information received } \\
\hline Keeping baby warm & $1 / 70$ & $1.4(0.04-7.7)$ \\
\hline Vaccination & $14 / 70$ & $20(11.4-31.3)$ \\
\hline Hygiene & $5 / 70$ & $7.1(2.4-15.9)$ \\
\hline Dry cord care & $8 / 70$ & $11.4(5.1-21.3)$ \\
\hline $\begin{array}{l}\text { Recall receiving information } \\
\text { from health care provider } \\
\text { on danger signs of newborn } \\
\text { illness }^{\text {a }}\end{array}$ & 23/174 & $13.2(8.7-19.2)$ \\
\hline $\begin{array}{l}\text { Recall receiving information } \\
\text { from health care provider } \\
\text { on breastfeeding }\end{array}$ & 109/174 & $62.6(55.0-69.8)$ \\
\hline \multicolumn{3}{|l|}{ Childbirth Care Satisfaction } \\
\hline \multicolumn{3}{|l|}{ Overall satisfaction with services } \\
\hline Somewhat or very satisfied & $160 / 174$ & $92.0(86.9-95.5)$ \\
\hline Would return to this facility again & $170 / 174$ & $97.7(94.2-99.4)$ \\
\hline $\begin{array}{l}\text { The health worker provided your } \\
\text { baby with the best care possible }\end{array}$ & $151 / 174$ & $86.8(80.8-91.4)$ \\
\hline
\end{tabular}

aDanger signs of the newborn illness: not feeding well, reduced activity, lethargic, fast breathing, fits/convulsions, fever, feels cold

universal for all newborns, skin-to-skin contact was not often practiced. This finding is consistent with studies from sub-Saharan Africa where immediate drying is commonly practiced by birth attendants, but not skin-to-skin contact [25]. Observation studies in Ethiopia, Rwanda, Tanzania, Kenya, and Madagascar also reported less than $60 \%$ of women practicing immediate skin-to-skin contact [25]. Similarly, a study in South Sudan, a protracted crises situation, had lower proportions of women practicing skin-toskin contact at the primary health facility level as compared to the hospital [26]. In our study, skin-to-skin contact was not emphasized on pre-discharge education to mothers and only one mother in the postnatal interview recalled receiving messaging on the importance of skin-to-skin contact. A systematic review by Moore and colleagues [30] showed that skin-to-skin contact when practiced, promoted breastfeeding and stabilization of the healthy term newborn. The benefits of skin-to-skin contact for stability of the cardio-respiratory system and thermal control among low-birth-weight (LBW) and preterm infants have been reported by earlier studies [30,31], in our study, while $2.4 \%$ of births were preterm, there was no statistically significant association between gestational age and skin-to-skin contact.

Overall, less than half (40.2\%) of mothers received educational messages on any aspect of newborn care. Studies have shown that mothers are more likely to breastfeed if breastfeeding is initiated early and mothers receive support on how to breastfeed [31]. Though necessity of breastfeeding was the most prevalent observed message delivered to mothers prior to discharge (16.5\%) and the most commonly recalled by mothers in the postnatal interview $(62.6 \%)$, the support provided to mothers to initiate breastfeeding $(18.7 \%)$ and the percentage that started immediate breastfeeding (30.1\%) was much lower than similar studies in conflict settings in sub-Saharan Africa where early immediate breastfeeding was above $90 \%[25,26]$.

Hygienic practices by health care workers during childbirth are vital to reduce health care-associated infections [33]. Nearly all births were attended by health care workers who wore clean or sterile gloves for examination and for attending births. However, handwashing with soap prior to delivery care was practiced by few health workers. The low prevalence of handwashing by health care workers may be due to low adherence to standard practices or low knowledge by service providers. In high neonatal mortality settings such as Somalia, the WHO recommends the application of chlorhexidine (antiseptic gel or solution) to the umbilical stump for infants born at home and dry cord care at health facility level [24]. Our study was focused on deliveries attended at the health facility level, which found that dry cord care was practiced on $41 \%$ of infants. In such settings, where hygienic practices are not adhered to, it may be beneficial to consider the use of chlorhexidine for cord care at the facility level.

Intrapartum care and readiness to manage birth asphyxia was low, which is of concern given the number of stillbirths reported $(n=7)$ and the possibility that some of the stillbirths may be due to intrapartum complications or fetal distress that was not detected or managed early [34, 37]. Studies on stillbirths have suggested that intrapartum-related stillbirths, may be preventable with improved intrapartum care with partograph use and early action to manage complications [16].

Length of stay following childbirth in health facilities is recognized as a critical time to educate mothers on newborn care and to identify and manage complications that may arise in the first $24 \mathrm{~h} \mathrm{[35].} \mathrm{In} \mathrm{our} \mathrm{study,} \mathrm{the} \mathrm{median}$ length of stay following childbirth ( $4 \mathrm{~h}$ and $37 \mathrm{~min}$ ) was shorter than previous studies in developing countries where length of stay ranged from 1.3 days to 6.2 days for vaginal deliveries [35]. The lack of space in the labor room and maternity waiting area could have contributed to the short length of stay. This short length of stay presents a challenge for health care workers in providing key information to mothers before discharge. In our study, few mothers were observed receiving messages on thermal care, cord care, feeding or danger signs and this low level of health messaging was also reflected in the home interviews. This is a missed opportunity, especially in contexts like Bossaso, where mothers may not return for postnatal 


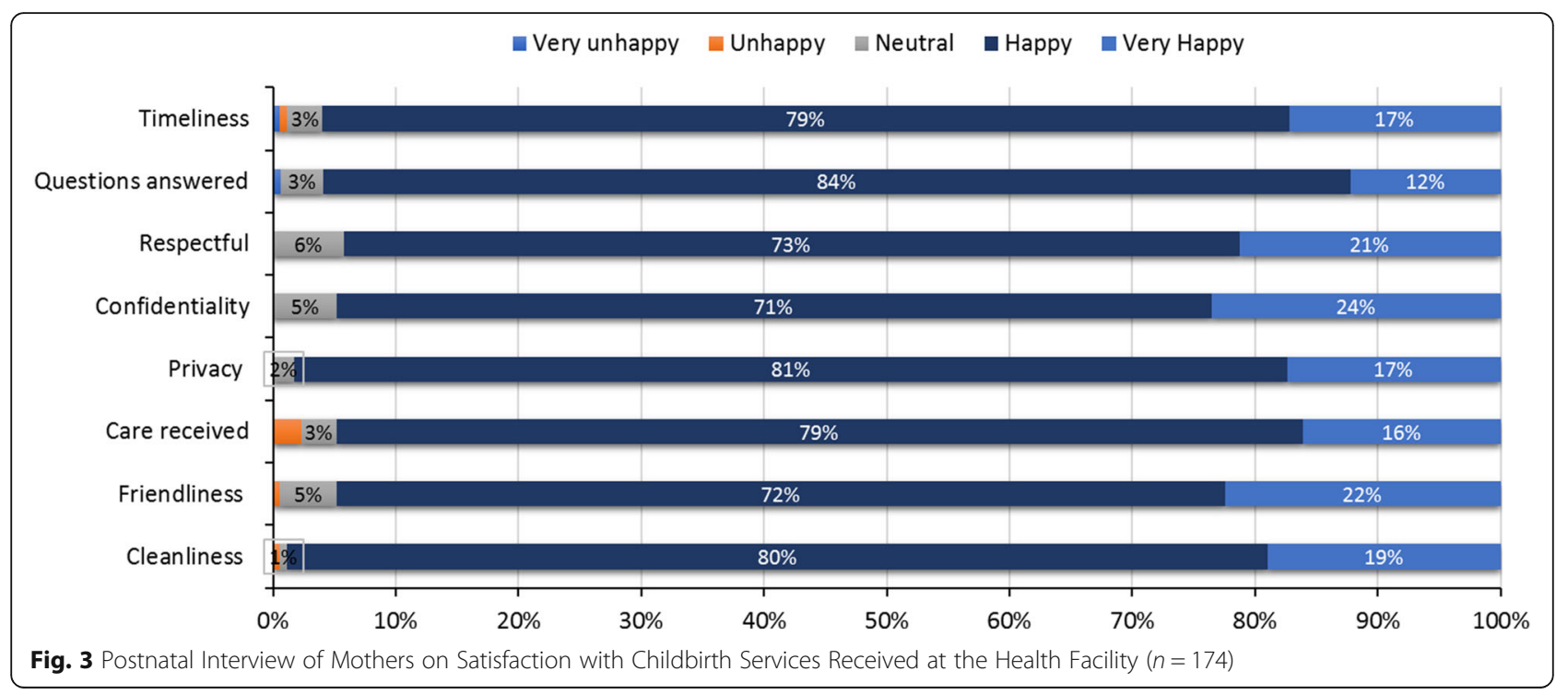

check-ups and have few additional encounters with the healthcare system. The short length of stay after childbirth and the providers' level of knowledge and training could have contributed to the low proportion of women that received educational messages.

Most of the mothers interviewed as part of this study reported being happy or very happy with the services they received at the health center. This finding was consistent across the four health facilities and across the eight domains (cleanliness, friendliness, respect, confidentiality, care provided, timeliness, received answer to questions, and privacy). This positive reporting from mothers is encouraging and is higher than in similar studies in sub-Saharan Africa [36]. However, among the five women who responded unhappy or very unhappy, two were unhappy across multiple domains and four out of five were unhappy with care provided. Future studies should follow this qualitative finding with in-depth interviews.

In situations where intrapartum care does not include early recognition of complications by using partographs and timely management of obstetric complications, it is difficult to distinguish deaths due to intrapartum complications from other causes [34]. Therefore, examining both stillbirths and early neonatal deaths is important in evaluating the effectiveness of interventions. Earlier studies on effectiveness of the WHO essential newborn training package have shown statistically significant reductions of early newborn deaths after service providers received the essential newborn training [32, 37]. Training of the midwives and nurses in Bossaso on essential newborn care is crucial to improve quality of care and to decrease newborn mortality.

Our study found significant variation by health facility in the practice of skin-to-skin contact, support in the initiation of breastfeeding, initiation of immediate breastfeeding, handwashing, and dry cord care. Further study is needed to understand what factors contributed to these variations, as the data shows the percent of births attended by a skilled health worker was similar in all four health facilities. Identification of the specific reasons behind the variations will help target support given to facilities and health care workers in order to improve the consistency and quality of newborn care provision in these contexts. Essential newborn interventions are evidence-based lifesaving interventions and it is critical that these interventions are available at quality levels to improve newborn survival in conflict settings.

\section{Strengths and limitations}

This study focused on the provision and quality of essential newborn care provided during labor, delivery and the immediate postnatal period. The findings provide critical baseline information on coverage and gaps of evidencebased newborn care interventions in humanitarian contexts. Using observation of practice rather than clinical records provides greater data accuracy. Observing the delivery of information to mothers by health care providers and asking mothers about what information they recalled receiving approximately 1-week postnatal gives insight on whether key messages are delivered effectively.

The study had several limitations. A high percentage (28\%) of mothers were lost to follow-up or refused postnatal interview at home. These women may have had different experiences of satisfaction, maternal knowledge, and newborn complications in the first week of life than those reported by the interviewed women. It is possible that the childbirth satisfaction results underestimated dissatisfaction, as women may have responded positively due to social desirability bias. Additionally, women who were excluded from the interviews because 
of an adverse birth outcome (stillbirth or early neonatal death) may have had different levels of satisfaction in care. Another limitation is that the presence of observers may have altered the behavior and practice of service providers [38]. The service providers were aware that their practice was being observed for research purposes and may have performed differently than if they were not observed. However, this effect could have been minimized by having observers from Bossaso who were not affiliated with the Ministry of Health and who were on a similar professional level as the observed service providers.

Finally, pregnant women with early signs of complications were referred to the hospital and were not enrolled in this study. It is possible that the findings of the study are an underestimation of maternal and newborn complications and adverse outcomes. In addition, as the health facilities were purposely selected for this study, our findings have limited generalizability.

\section{Conclusion}

In conclusion, this study provides baseline information on essential newborn practice in selected health facilities in Bossaso, Somalia, a protracted conflict situation. Essential newborn care was not universally practiced and there was variation in practice by health facility. The implementation of the Field Guide [14] has the potential to improve newborn practice through the training of service providers and the delivery of newborn care education to mothers.

\section{Endnotes}

${ }^{1}$ Delayed bathing, the WHO recommends that bathing should be delayed for at least $6 \mathrm{~h}$ from birth. We were unable to ascertain the $6 \mathrm{~h}$ delay as some mothers were discharged from the health facility early. This indicator was modified to measure delayed bathing up to time of discharge from health facility.

${ }^{2}$ Exact count agreement divided by total count. 3600/ 3807

${ }^{3} \mathrm{WHO}$ recommendations on antenatal care for positive pregnancy experience: WHO 2016. Was released at the time of the study. The revised antenatal care model recommends a minimum of eight contacts/visits during pregnancy while the guidance prior to 2016 was four contacts/visits.

\section{Abbreviations \\ CDC: U.S. Centers for Disease Control and Prevention; IDPs: Internally Displaced Persons; WHO: World Health Organization}

\section{Acknowledgements}

We would like to acknowledge the Ministry of Health in Bosasso, Somalia and the in-charge for the four health facilities for organizational support for the study and providing access to the health facilities. We extend a special acknowledgement to health workers, observers, data clerks, and interviewers for the substantial amount of time they invested in the successful completion of the study. The authors would also like to make a special acknowledgement to the women who participated in the study for their invaluable support.

\section{Funding}

Funding was provided through a grant from the United States Centers for Disease Control and Prevention.

\section{Availability of data and materials}

All relevant data used and/or analyzed for the study are available in anonymized form from the corresponding author on reasonable request.

\section{Declarations}

The findings and conclusions in this report are those of the authors and do not represent the official position of the Centers for Disease Control and Prevention.

\section{Authors' contributions}

RA contributed substantially to the conception, design, analysis, interpretation of results, and drafting of this article. CNM contributed substantially to the design, implementation, and analysis, interpretation of results and drafting of the article. AC contributed substantially to the conception, design, implementation, and interpretation of the results presented in this article. $\mathrm{MH}$ and $\mathrm{EH}$ contributed substantially to the design, analysis, and interpretation of results presented in this article. KC and SJ contributed to the design, implementation, interpretation of the results, and drafting of this article. SB contributed to the design and implementation of the study. AS, and AC contributed to the analysis and interpretation of results. All authors have read and approved the final version of this manuscript.

\section{Ethics approval and consent to participate}

The health workers and women in labor provided verbal consent on birth observation. Women who were under the age of 18 years provided ascent and their parents or husband provided verbal consent. Women provided verbal consent for home follow-up and postnatal interview. The study protocol was submitted to the Ministry of Health, Save the Children Ethnics Review Committee and CDC. Permission was obtained from the three institutions.

\section{Competing interests}

The authors declare that they have no competing interests.

\section{Publisher's Note}

Springer Nature remains neutral with regard to jurisdictional claims in published maps and institutional affiliations.

\section{Author details}

${ }^{1}$ Emergency Health, Department of Global Health, Save the Children, 2275 Sutter Street, San Francisco, CA 94115, USA. ${ }^{2}$ Department of Global Health, Save the Children, 899 North Capitol Street NW, Suite 900, Washington, DC 20002, USA. ${ }^{3}$ Save the Children in Somalia, Lavington, Nairobi, Kenya. ${ }^{4}$ Center for Global Health, US Centers for Disease Control and Prevention, 1600 Clifton Rd., Atlanta, GA 30329-4027, USA. ${ }^{5}$ Save the Children in Somalia, Lavington, Nairobi, Kenya. ${ }^{6}$ Department of Global Health, Save the Children, 899 North Capitol Street NW, Suite 900, Washington, DC 20002, USA.

Received: 20 August 2018 Accepted: 2 May 2019

Published online: 13 June 2019

\section{References}

1. Humanitarian Coalition: What is a humanitarian emergency? https://www. humanitariancoalition.ca/info-portal/factsheets/what-is-a-humanitarian-crisis (Accessed 16 Dec 2018).

2. Salama P, Spiegel P, Talley L, Waldman R. Lessons learned from complex emergencies over past decade. Lancet. 2004;364:1801-13.

3. Food and Agriculture Organization of the United Nations (FAO). Countries in protracted crisis: what are they and why do they deserve special attention? Common features of countries in protracted crisis. The State of Food Insecurity in the World 2010. 
4. United Nations High Commissioner for Refugees. Global trends: forced displacement in 2015. https://www.unhcr.org/5b27be547.pdf. Accessed 16 Dec 2018.

5. Toole MJ, Waldman RJ. The public health aspects of complex emergencies and refugee situations. Ann Rev Pub Health. 1997;18:283-312.

6. Moss WJ, Ramakrishnan M, Stoms D, Siegle A, Weiss WM, Lejnev I, Muhe L. Child Health in Complex Emergencies. WHO Bull. 2006;84(1):58-64.

7. UNICEF, WHO, The World Bank, United Nations. Levels \& Trends in Child Mortality: Report 2018. Estimates developed by the UN Inter-agency Group for Child Mortality Estimation. New York: UNICEF; 2018.

8. Spiegel P, Checchi F, Colombo S, Paik E. Health-care needs of people affected by conflict: future trends and changing frameworks. Lancet. 2010; 375:341-5.

9. Wise PH, Darmstadt GL. Confronting stillbirths and newborn deaths in areas of conflict and political instability: a neglected global imperative. Pediatr In Child Health. 2015;35(3):220-6. https://doi.org/10.1179/2046905515y.0000000027.

10. Blanchet K, Ramesh A, Frison S, Warren E, Hossain M, Smith J, et al. Evidence on public health interventions in humanitarian crises. Lancet. 2017; 390(10109):2287-96. https://doi.org/10.1016/s0140-6736(16)30768-1.

11. Liu L, Oza S, Hogan D, Chu Y, Perin J, Zhu J, et al. Global, regional, and national causes of under-5 mortality in 2000-15: an updated systematic analysis with implications for the sustainable development goals. Lancet (London, England). 2016. https://doi.org/10.1016/S0140-6736(16)31593.

12. Lawn JE, Cousens S, Zupan J. 4 million neonatal deaths: when? Where? Why? Lancet. 2005;365(9462):891-900. https://doi.org/10.1016/s01406736(05)71048-5.

13. Lam JO, Amsalu R, Kerber K, Lawn JE, Tomczyk B, Cornier N, et al. Neonatal survival interventions in humanitarian emergencies: a survey of current practices and programs. Confl Health. 2012;6(1):2. https://doi.org/10.1186/ 1752-1505-6-2.

14. United Nations Children's fund (UNICEF), and save the children. Newborn health in humanitarian setting field guide interim version. 2016. http://iawg. net/wp-content/uploads/2016/08/Newborn-Health-in-HumanitarianSettings-Field-Guide-Interim-Version-1.pdf

15. World Health Organization. Essential newborn care course: clinical practice book. Geneva: World Health Organization; 2010.

16. Darmstadt GL, Bhutta ZA, Cousens S, Adam T, Walker N, de Bernis L. Evidence-based, cost-effective interventions: how many newborn babies can we save? Lancet. 2005;365(9463):977-88. https://doi.org/10.1016/s01406736(05)71088-6.

17. WHO, UNFPA, UNICEF. Pregnancy, childbirth, postpartum and newborn care: a guide for essential practice (PCPNC). 3rd ed. Geneva: World Health Organization; 2015

18. Internal Displacement Monitoring Center (IDMC): Somalia country information http://www.internal-displacement.org/countries/somalia/. Accessed 24 Jan 2018

19. United Nations Office for the coordination of humanitarian affairs (OCHA): Somalia context overview 2016. http://www.unocha.org/somalia/aboutocha-somalia/crisis-overview. Accessed 24 Jan 2019.

20. UNICEF and Ministry of Planning and International Cooperation. Northeast Zone Multiple Indicator Cluster Survey. Nairobi; 2011. http://microdata. worldbank.org/index.php/catalog/2551/datafile/F24/N3110. Accessed on 24 Jan 2019

21. Digglep P, Liang KY, Zeger S. Analysis of Longitudinal Data. Oxford: Clarendon Press; 1994

22. Goodman P, Mackey MC, Tavakoli AS. Factors related to childbirth satisfaction. J Adv Nurs. 2004;46(2):212-9. https://doi.org/10.1111/j.13652648.2003.02981.

23. Siassakos D, Clark J, Sibanda T, Attilakos G, Jefferys A, Cullen L, et al. A simple tool to measure patient perceptions of operative birth. Bjog. 2009; 116(13):1755-61. https://doi.org/10.1111/j.1471-0528.2009.02363.

24. WHO recommendations on postnatal care of the mother and newborn. Geneva: World Health Organization; 2013. http://apps.who.int/iris/bitstream/ 10665/97603/1/9789241506649_eng.pdf.

25. de Graft-Johnson J, Vesel L, Rosen HE, Rawlins B, Abwao S, Mazia G, et al. Cross-sectional observational assessment of quality of newborn care immediately after birth in health facilities across six sub-Saharan African countries. BMJ Open. 2017;7(3):e014680. https://doi.org/10.1136/bmjopen2016-014680.

26. Sami S, Kenyi S, Amsalu R, Tomczyk B, Jackson D, Meyers J, Greeley M, Dimit AM, Scudder E, Kerber K. Implementing Newborn Care Services in Humanitarian
Settings: Barriers and Facilitators to Implementation at the Community and Facility Level in Displaced Person Camps in South Sudan. Annals of Global Health. 2017. https://doi.org/10.1016/j.aogh.2017.03.305 https://www. annalsofglobalhealth.org/articles/abstract/10.1016/j.aogh.2017.03.305/.

27. KoBo toolbox. http://www.kobotoolbox.org/. Accessed 24 Jan 2019.

28. Bernard HR. Research methods in anthropology: qualitative and quantitative approaches. 2nd ed. Newbury Park: Sage; 1994.

29. Oswald D, Sherratt F, Smith S. Handling the Hawthorne effect; The challenges surrounding a participant observer. Rev Soc Stud (RoSS). 2014; 1(1) Autumn.

30. Moore ER, Bergman N, Anderson GC, Medley N. Early skin-to-skin contact for mothers and their healthy newborn infants. Cochrane Database Syst Rev. 2016;11:Cd003519. https://doi.org/10.1002/14651858.CD003519.pub4.

31. Conde-Agudelo A, Diaz-Rossello JL. Kangaroo mother care to reduce morbidity and mortality in low birthweight infants. Cochrane Database Syst Rev. 2016;(8):Cd002771. https://doi.org/10.1002/14651858.CD002771.pub4.

32. Malhotra S, Zodpey SP, Vidyasagaran AL, Sharma K, Raj SS, Neogi SB, et al. Assessment of essential newborn care services in secondary-level facilities from two districts of India. J Health Popul Nutr. 2014;32(1):130-41.

33. Pessoa-Silva CL, Hugonnet S, Pfister R, Touveneau S, Dharan S, Posfay-Barbe K, Pittet D. Reduction of health care associated infection risk in neonates by successful hand hygiene promotion. Pediatrics. 2007;120(2):e382-90. https:// doi.org/10.1542/peds.2006-3712.

34. Lawn JE, Lee AC, Kinney M, Sibley L, Carlo WA, Paul VK, et al. Two million intrapartum-related stillbirths and neonatal deaths: where, why, and what can be done? Int J Gynaecol Obstet. 2009;107(Suppl 1):S5-18, s19. https:// doi.org/10.1016/j.jjgo.2009.07.016.

35. Campbell OM, Cegolon L, Macleod D, Benova L. Length of stay after childbirth in 92 countries and associated factors in 30 low- and middleincome countries: compilation of reported data and a cross-sectional analysis from nationally representative surveys. PLoS Med. 2016;13(3): e1001972. https://doi.org/10.1371/journal.pmed.1001972.

36. Okonofua F, Ogu R, Agholor K, Okike O, Abdus-Salam R, Gana M, et al. Qualitative assessment of women's satisfaction with maternal health care in referral hospitals in Nigeria. Reprod Health. 2017;14(1):44. https://doi.org/10. 1186/s12978-017-0305-6

37. Carlo WA, Goudar SS, Jehan I, Chomba E, Tshefu A, Garces A, et al. Newborn-care training and perinatal mortality in developing countries. $\mathrm{N}$ Engl J Med. 2010;362(7):614-23. https://doi.org/10.1056/NEJMsa0806033.

38. McCambridge J, Witton J, Elbourne DR. Systematic review of the Hawthorne effect: new concepts are needed to study research participation effects. J Clin Epidemiol. 2014;67(3):267-77. https://doi.org/10.1016/j.jclinepi.2013.08.015.

\section{Ready to submit your research? Choose BMC and benefit from:}

- fast, convenient online submission

- thorough peer review by experienced researchers in your field

- rapid publication on acceptance

- support for research data, including large and complex data types

- gold Open Access which fosters wider collaboration and increased citations

- maximum visibility for your research: over $100 \mathrm{M}$ website views per year

At $\mathrm{BMC}$, research is always in progress.

Learn more biomedcentral.com/submissions 